\title{
LA FUNDACIÓN EN MAQUIAVELO: NOTAS PRELIMINARES*
}

\author{
Daniel Mansuy** \\ http://orcid.org/0000-0002-9861-1509 \\ dmansuy@uandes.cl
}

RESUMEN El presente artículo busca determinar el sentido de la fundación política en el pensamiento de Maquiavelo, a partir de lo señalado en el capitulo VI del Príncipe. Nuestra hipótesis es que, en dicho texto, el Secretario florentino introduce la idea según la cual la auténtica fundación política debe ser realizada sobre una materia completamente informe y disponible. Dado que los fundadores míticos tuvieron una ocasión ideal para hacer algo así, el trabajo de los fundadores históricos es intentar recrear - en la medida de lo posible-aquellas condiciones ideales de fundación, lo que exige aplicar grados muy elevados de violencia. Esta perspectiva maquiaveliana es, de algún modo, el punto de partida de buena parte del pensamiento político moderno.

Palabras clave Maquiavelo; Fundación política; Pensamiento político moderno.

ABSTRACT This article tries to assess the sense of Political Foundation in Machiavelli's thought, based on his statement in Chapter VI of The Prince. Our hypothesis is that - in this text - the Florentine secretary introduces the idea by which true political foundation must be carried out on matter completely devoid of form and fully available. Given that the mythical founders were presented with an ideal situation to undertake such a thing, the work of the

* Artigo submetido em 02/09/2018 e aprovado em 27/03/2019. Este artículo ha sido realizado con el apoyo de Fondecyt (proyecto n. 11160873).

** Universidad de los Andes. Santiago, Chile.

KRITERION, Belo Horizonte, nº 144, Dez./2019, p. 513-535 
historical founders is to try to recreate - when possible - those ideal founding conditions, which demands the application of very high levels of violence. This Machiavellian perspective is - in some way - the starting point of a major portion of the modern political thought.

Keywords Machiavelli; Political Foundation; Modern Political Thought.

En su lectura de los trabajos de Maquiavelo, Claude Lefort suele marcar el contraste existente entre el pensamiento del secretario florentino y la filosofía de Aristóteles. Para el exégeta francés, hay en Maquiavelo una crítica implícita a la ontología aristotélica, en la medida en que rechaza la idea según la cual el orden natural del mundo sería de reposo. Aunque Aristóteles observa con agudeza el movimiento propio de las cosas humanas, siempre lo analiza (según Lefort) a la luz de la estabilidad. En lo que respecta a las cuestiones sociales, Aristóteles nunca pierde de vista la idea de mejor régimen, y a partir de ella estudia los distintos órdenes existentes. Habría, entonces, desde la perspectiva del Estagirita, un criterio a partir del cual podría comprenderse el mundo, y también una estructura teleológica capaz de orientar la acción humana. La originalidad de Maquiavelo reside en romper frontalmente con ese dispositivo intelectual. En su lógica, la realidad no contiene nada que nos permita deducir algo así como un orden inmanente, sino sólo contingencia y plasticidad (Lefort, 1972, pp. 425 y ss.). A partir de esa especie de precariedad ontológica de la realidad social, la política puede pensarse como una constante apertura al acontecimiento (que marca una ruptura necesaria y radical respecto del pasado [Vatter, 2014]) más que como actualización de una naturaleza latente.

Quizás el momento más paradigmático de esa contingencia sea el de la fundación. En su Política, Aristóteles alude al fundador de la ciudad, pero lo hace de tal modo que su acción queda inscrita en la continuidad teleológica de la naturaleza: el fundador de la polis no hace más que hacer efectivo aquello que estaba en potencia. Al fundador, dice el Estagirita, le debemos los mayores bienes, pero descubre más que crea. De hecho, la mención de la fundación se encuentra plenamente integrada en la explicación del carácter natural de la polis (Aristóteles, 2007, I, 2, 1253a29-32)․․ Para Maquiavelo, las cosas son un 
poco distintas. En efecto, si no hay orden natural ni estructura teleológica que oriente la acción, entonces el papel del fundador es radicalmente distinto, pues debe hacer surgir algo que antes no estaba allí de ningún modo. Sus rasgos lo acercan más al demiurgo que al político virtuoso de Aristóteles, y eso explica la importancia que adquiere en su pensamiento.

En las páginas que siguen, intentaremos elucidar la figura del fundador maquiaveliano, tal cual aparece en El Príncipe, a la luz de estas observaciones de Lefort. Nos interesa analizar en qué medida la figura del fundador, y el hecho de la fundación, rompe con el paradigma aristotélico, y en qué medida remite (o no) a una eventual nueva ontología. La adecuada comprensión de este problema es especialmente importante porque permite situar a Maquiavelo en la historia del pensamiento político: si la fundación supone algún tipo de quiebre radical, entonces el pensador florentino pone quizás la primera piedra del gran edificio de la política moderna. Después de todo, consumar esa ruptura con el pensamiento aristotélico no tiene nada de trivial, y funciona como condición de posibilidad de todos los desarrollos posteriores. Si la fundación es más quiebre que continuidad, entonces la sociedad política tiene algo de artificio, que es la noción a partir de la cual trabajan los pensadores modernos $(C f$. Cruz-Prados, 1986).

Para intentar comprender esta cuestión, dividiremos nuestro trabajo en tres partes. En la primera de ellas, pondremos especial atención en el capítulo VI del Príncipe, donde Maquiavelo analiza algunos casos ejemplares de fundación. Estudiaremos luego las tres figuras que reciben el apelativo de "príncipe nuevo" en su opúsculo: César Borgia, Fernando de Aragón y el emperador Severo. Las acciones de estos tres hombres los acercan a la situación fundacional, en la medida en que supieron recrear una situación propicia para ejercer su poder. Por último, concluiremos con algunas reflexiones en torno a las consecuencias de la noción maquiaveliana de fundación y su relación con la cuestión de los humores sociales.

\section{Los fundadores en el capítulo VI del Príncipe}

En este capítulo, Maquiavelo nos ofrece la discusión más explícita sobre el fenómeno fundacional que sea posible encontrar en sus escritos. Allí, al hablar de los principados completamente nuevos (como se había anunciado al inicio del libro), el secretario florentino alude a los fundadores, excusándose por referirse a tan grandiosos ejemplos (grandissimi exempli). En efecto, estas figuras ejemplares parecen muy alejadas de la experiencia real y, por tanto, la imitación se vuelve difícil: ¿cómo inspirarnos en casos tan elevados? 
Maquiavelo ya vislumbra un tópico propio de la modernidad: nuestra relación con aquellos grandes hombres que parecen inimitables. Señala luego que, si queremos tener algo de la virtud de los más excelentes, debemos intentar imitarlos de algún modo; y, para ilustrar el punto, recurre a la metáfora del arquero. Éste debe apuntar muy alto, con el fin de lograr un objetivo más modesto. Dicho de otro modo, apuntamos alto no porque pretendamos alcanzar su nivel de excelencia, sino porque esa dirección nos deja lo más cerca posible de ellos ${ }^{2}$.

Estos hombres excelentes se caracterizan por haber llegado al principado por virtud más que por fortuna. Maquiavelo menciona cuatro ejemplos: Moisés, Rómulo, Ciro y Teseo. La enumeración es llamativa, en primer lugar, porque contiene una extraña mezcla. Hay un personaje bíblico, dos míticos y uno histórico. Es conocido el célebre paralelo establecido por Plutarco entre Teseo y Rómulo, pero ¿por qué agregar en ese contexto a Ciro y Moisés? Desde luego la primera respuesta es que, al reunir a cuatro figuras de naturaleza tan distinta, Maquiavelo busca hacernos ver que el acto fundacional es análogo en cada una de estas situaciones. En otras palabras, la fundación es siempre idéntica a sí misma, más allá de las singularidades de cada acto fundacional. Las diferencias eventuales entre religión, mitología e historia se diluyen a la luz de este fenómeno. Así, los cuatro personajes revelan un patrón común. Al mismo tiempo, Maquiavelo cumple otro propósito, pues rebaja tanto lo religioso como lo mítico al plano meramente histórico. La presencia de Ciro en la lista implica que la Biblia y la mitología pueden ser leídas en clave natural: Ciro hizo algo similar a lo realizado por Moisés, Rómulo y Teseo. Ahora bien, no hay sólo una degradación de la Biblia y de la mitología, sino que también un ascenso consecuente de la figura histórica (en este contexto, Ciro no tiene nada que envidiarle a Moisés o Rómulo); además de una puesta en equivalencia de la Biblia con la mitología ${ }^{3}$. Esto es importante porque, en la medida en que el Príncipe es un llamado a la acción, Maquiavelo indica que la fundación no es algo que esté fuera de nuestro alcance (y por eso la metáfora del arquero resulta

2 El ejemplo del arquero es utilizado por Aristóteles en el libro I de la "Ética", y es también recurrente en el Renacimiento italiano. En el caso del filósofo griego, la figura está puesta al servicio de la idea de perfección humana (debemos aspirar a ella aunque no podamos alcanzarla plenamente); aunque en Maquiavelo, como veremos, la intención es algo distinta. Ver el comentario a este pasaje de Jean-Louis Fournel y Claude Zancarini: Maquiavelo, (2000, pp. 269-270). También véase: Lefort (1972, p. 363); Aristóteles (1993, 1094a23-25).

3 El caso más llamativo es, desde luego, el de Moisés. Maquiavelo dice que lo realizado por Ciro y otros fundadores no dista mucho de lo realizado por Moisés, "que tuvo tan gran preceptor" (che ebbe si grande preceptore). La sugestión implícita es que no hay una distancia efectiva entre la mitología griega y la historia bíblica Cf. Benner (2013, pp. 72-73). En este trabajo, utilizamos la versión italiana de Corrado Vivanti (Maquiavelo, 1997); y seguimos -con mínimos cambios- las traducciones de Antonio Hermosa para El Príncipe, y de Luis Navarro para los Discursos Cf. Maquiavelo (2011). 
equívoca). El secretario florentino quiere inducirnos a pensar que la fundación aún es posible, y por eso Ciro es quizás el personaje más relevante de la lista.

Ahora bien, ¿por qué estos fundadores merecen tanta admiración? ¿Cómo y por qué lograron gestas cuya memoria no se extingue? Para Maquiavelo, esto se debe a que la fortuna sólo les dio la ocasión para fundar, mientras que el resto corrió por cuenta de su virtud. En sus propias palabras,

Al escrutar sus vidas y sus acciones no se percibe que obtuvieran otra cosa de la fortuna que la ocasión, la cual les proporcionó la materia en la que introducir la forma que les pareció. Sin dicha ocasión se habría perdido la virtud de sus ánimos, y sin dicha virtud, la ocasión se habría dado en vano (2011, VI).

Este breve pasaje es crucial para comprender el propósito de Maquiavelo. Por un lado, introduce la doctrina de la fortuna: en estos casos excelsos, ella sólo brinda la ocasión; esto es: sólo ofrece la oportunidad. Los fundadores, desde luego, saben aprovecharla, y sin virtud aquella ocasión no habría servido de nada. Pero, recíprocamente, la virtud también es vana en ausencia de oportunidad. La fundación requiere de una feliz coincidencia entre ambos factores (veremos más adelante si es posible suplir, eventualmente, la falta de ocasión). La segunda dimensión interesante de este pasaje viene dada por la descripción que Maquiavelo realiza de la acción del fundador: la ocasión proporciona la materia en la que el fundador plasma una forma.

Nos parece que hay aquí un indicio relevante para leer correctamente a Maquiavelo: lo propio del fundador es tener, o encontrarse con, una materia disponible, que permite plasmar una determinada forma. La fórmula no deja de ser llamativa para quien conozca, aunque fuera lejanamente, la escolástica medieval, pues hay una referencia implícita a la materia prima, carente de toda forma. La principal característica de la materia prima es ser pura potencia, esto es, moldeable plenamente por una forma externa. Tomás de Aquino lo explica diciendo que la materia prima no es ser "más que en potencia", una especie de no-ser, "porque le falta algo de lo que está privado de por sí" (Aquino, 1964. I, q. 5, a. 4). Esto, siempre según el Aquinate, tiene consecuencias que son interesantes para nuestro estudio. Por un lado, es imposible realizar cualquier tipo de distinción en la materia prima (Aquino, 1964, I, q. 16, a. 7; q. 66, a. 1); y, además, ésta sólo es cognoscible por su relación con la forma (Aquino, 1964, I, q. 87, a. 1). La materia prima del fundador es un pueblo sin forma, sin gobierno, sin arché: en un principio, había un pueblo incognoscible a la espera de quien le infundiera una forma (Roeckelin, 2014, p. 130). Pero, ¿en qué sentido un pueblo podría ser analogable a la materia prima? ¿Qué quiere decir esta extraña metáfora? 
Maquiavelo intenta explicarlo resumiendo muy brevemente la ocasión que recibió cada uno de sus cuatro personajes. Moisés encontró en Egipto al pueblo de Israel esclavizado y oprimido; Rómulo fue abandonado en su nacimiento y no encontró su lugar en el Alba (y eso le dio la libertad de acción); Ciro encontró a los persas descontentos con el poder de los medos; y Teseo no habría mostrado su virtud si los atenienses no hubieran estado dispersos. Más allá de la singularidad del caso de Rómulo (cuya ocasión no está vinculada a un pueblo [Benner, 2013, p. 76]), los cuatro fundadores quedan en estado de estricta igualdad: cada uno de ellos encontró una ocasión favorable para mostrar su virtud; cada uno de ellos tuvo un pueblo en el que plasmar una forma determinada. Pueblos esclavizados, oprimidos, dispersos y descontentos del poder: tal parece ser el rasgo común que define este tipo de ocasión. El momento fundacional se define entonces por esta extraordinaria libertad que da una materia sin forma: el fundador puede infundir, sin restricciones de ninguna especie, aquella forma que le parece más adecuada. El fundador puede informar una materia sin encontrar oposición ni resistencia: tal es la extraordinaria posibilidad que les fue ofrecida.

Ahora bien, nuestro autor sabe que estos ejemplos funcionan como paradigma y, como tal, no carecen de limitaciones. En efecto, ¿quién podría esperar una ocasión análoga a la que ellos tuvieron? Dado que tal cosa es (muy) poco probable, Maquiavelo aborda el problema que realmente le interesa: ¿cómo emular a los fundadores sabiendo que no tendremos una ocasión tan pura y desprovista de condicionamientos? Aquellos que quieren imitar, dice Maquiavelo, se encuentran con grandes dificultades, pues deben introducir nuevos modos y nuevos órdenes para fundar el estado y garantizar su seguridad; no hay nada más peligroso que "estar en el origen de la introducción de nuevos órdenes" (Cf. Maquiavelo, 1997, Vol. 1, p. 197) ${ }^{4}$. En concreto, esto implica que allí donde el fundador original tiene plena libertad para plasmar una forma, el político más rutinario se encuentra con una situación distinta: si acaso quiere imitar al fundador introduciendo nuevos órdenes, enfrentará necesariamente una resistencia que no tendrá nada de pacífica. Los innovadores tienen por enemigos a todos quienes se beneficiaban con el orden antiguo y, por otro lado, sólo tiene tibios defensores en quienes podrían beneficiarse del nuevo (las causas de la tibieza son el miedo y la incredulidad). Quien aspire a innovar al interior de un orden existente se encuentra entonces con una dificultad adicional respecto del fundador, pues debe ser capaz de inventarse la ocasión, debe ser capaz de recrear las condiciones de la fundación. Esto implica un quiebre 
violento con la rutina propia de la vida política: el innovador tiene que romper abrupta y violentamente con ella si quiere imponer aquello que el Florentino llama nuevos órdenes. Cabe entonces formular la pregunta: ¿es más difícil fundar desde la situación original, o innovar al interior de un cuadro concreto? Desde luego, el fundador tiene una virtud especial que le permite crear un poco ex nihilo, pero la verdad es que el político que quiere introducir nuevos órdenes debe, mediante sus propias acciones, recrear aquella ocasión que al fundador le fue dada. La jerarquía inicial parece entonces invertida: si al principio del capítulo, la retórica indicaba que aquellos hombres excelentes son virtualmente insuperables en virtud, lo que sigue tiende a poner en duda esa tesis. Si el fundador recibe una materia prima, el político innovador debe lograr que una sociedad dotada de forma se vuelva, de algún modo, informe. La tarea parece ser bastante más difícil y peligrosa.

Para lograr imponer los nuevos órdenes el innovador debe cumplir con una primera condición indispensable: depender de sí mismo, para poder forzar las situaciones en su propio beneficio. Los profetas armados, dice Maquiavelo, vencen; mientras que los desarmados van a su ruina:

Moisés, Ciro, Teseo y Rómulo no habrían podido hacer observar por tan largo tiempo sus ordenamientos de haber estado desarmados, tal como en nuestros días acaeció a Savonarola; éste, en efecto, se hundió junto con sus instituciones en cuanto la multitud le retiró su confianza [...] Tales hombres, ciertamente, se mueven entre obstáculos difíciles y hallan su camino erizado de peligros, que han de superar con su virtud; mas, superados al fin, y habiéndoseles empezado a venerar, una vez que eliminan a quienes sienten envidia de sus atributos perduran poderosos, seguros, honrados y felices (Maquiavelo, 2011, VI).

Este pasaje contiene varios elementos dignos de destacar. Por de pronto, Maquiavelo confirma nuestra intuición anterior, al señalar que los cuatro fundadores son profetas. Como dijimos, se trata de un extraño modo de rebajar a los profetas auténticos (pues explicita la igualación de Moisés y Ciro), elevando al mismo tiempo a los fundadores (al sugerir que su virtud está vinculada con la profecía) (Ménissier, 2010, p. 257). Maquiavelo disuelve así nuevamente la distinción de planos religioso, mítico e histórico: para su propósito, sólo cabe una óptica para mirar la realidad, y acercarse a la verdad efectiva de la cosa. Por otro lado, Jerónimo de Savonarola funciona como perfecto contraejemplo de aquello que el innovador no debe hacer. Sus nuevos órdenes no fueron acompañados de la fuerza necesaria para que perduraran en el tiempo (por lo que cabe concluir que lo decisivo de la acción de Moisés no viene dado por la Providencia sino -como veremos- por el uso de la fuerza). La auténtica fundación debe darse los medios para coaccionar a quienes dejan de creer. 
Pero Maquiavelo añade algo más: el innovador supera los peligros y es venerado una vez que ha eliminado a quienes lo envidian. Nos encontramos aquí con un elemento crucial, pues la dificultad que debe enfrentar el fundador es la envidia: hay otros individuos que también aspiran a ocupar el lugar principal, y ellos son naturalmente enemigos de la nueva situación. El innovador debe limpiarse el camino, y por eso nuestro autor alude con insistencia a la necesidad de una ruptura abrupta y violenta. Recrear la situación fundacional, aquella donde el pueblo es análogo a la materia prima, implica eliminar las distinciones efectivamente presentes (ya sabemos que la materia prima no admite distinciones interiores). Los notables son, sin duda, los principales adversarios de cualquier nuevo orden. No hay fundación posible sin eliminación previa de las diferencias internas. Por lo mismo, el innovador debe estar dispuesto (como veremos) a ejercer niveles muy elevados de violencia si quiere consolidar su orden. En el fondo, debe retirarle la forma a la materia antes de infundir una nueva. Naturalmente, para lograrlo debe tener en cuenta las particularidades propias de la sociedad-que siempre las hay-, pero siempre teniendo en mente ese objetivo final.

Una alusión a Moisés presente en los Discursos explicita la posición de Maquiavelo, porque combina los elementos que hemos expuesto hasta aquí. En III, 30, se dice que la envidia puede ser eliminada de dos modos. El primero se emplea cuando abunda el miedo, y los hombres se disponen a obedecer: en situaciones de peligro, los individuos son más dóciles que de costumbre. El otro modo de extinguir la envidia, sigue Maquiavelo, consiste en matar a aquellos que no pueden aceptar la preponderancia de otro, y que están dispuestos a arruinar la patria para satisfacer sus apetitos. Por lo mismo, "el único remedio para vencer esta envidia es la muerte del que la alimenta" (Maquiavelo, 2011, III, p. 30). En otras palabras, si se quiere adquirir auténtica autoridad, es indispensable asesinar a los envidiosos. Maquiavelo grafica la lección recurriendo a Moisés: quien lea "sensatamente" la Biblia, podrá ver cómo éste se vio obligado a "matar a muchísimos hombres" que obstaculizaban sus proyectos (Ibid.). Desde luego, estos dos modos son perfectamente complementarios: la eliminación de los envidiosos produce miedo en aquellos que han sobrevivido. Maquiavelo se refiere con frecuencia a este tipo de casos, como si a través de ellos pudiera accederse a una verdad política fundamental. Por dar solo dos ejemplos, Clearco, tirano de Heraclea, se enfrentó a un grupo de nobles insolentes y, para librarse de ellos y satisfacer al pueblo, decidió cortarlos a todos en pedazos, "con extrema satisfacción del pueblo" (Maquiavelo, 2011, I, p. 16) y Cléomenes, rey de Esparta, hizo matar a todos los éforos " $y$ a cualquiera que pudiera oponerse 
a sus designios" (Ibid. I, 9) . Esto nos recuerda una lección muy presente en los Discursos: el fundador debe estar solo, pues la soledad es condición de su éxito (Maquiavelo, 2011, I, 9) ${ }^{6}$.

Maquiavelo concluye el capítulo VI del Príncipe de un modo que refuerza lo que hemos sugerido. En efecto, suma un ejemplo a su heterogéneo elenco de fundadores, innovadores y profetas: Hierón de Siracusa. ¿Qué relación tiene Hierón, un tirano de segundo orden con los grandes ejemplos anteriores? ¿La figura del arquero no nos incitaba acaso a apuntar lo más alto posible? El secretario florentino admite que se trata de un caso menor; pero asevera que este ejemplo es representativo de todos los semejantes (per tutti gli altri simili). Hierón sería entonces el complemento decisivo para dar cuenta del fenómeno fundacional, y cierra así el capítulo. Faltaba añadir a Hierón para que el cuadro fundacional quedara completo. Desde luego, sabemos que Hierón no fue ni fundador ni profeta. Tampoco fue, propiamente hablando, un príncipe. ¿Cuál podría ser entonces su función? Un motivo posible podría ser mostrar, con un ejemplo menos grandilocuente, qué camino debería seguir un nuevo Savonarola. El caso de Hierón parece mostrar que para fundar no es necesario ser personaje bíblico ni mítico, y ni siquiera gran personaje histórico. Hierón de algún modo radicaliza el indicio dado por Ciro: la gloria es más democrática de lo que parece. Así, la distinción entre los fundadores gloriosos y los políticos más silvestres a la que alude la metáfora del arquero va perdiendo su nitidez inicial (Lefort, 1972, p. 370) ${ }^{7}$.

Hierón, como los ejemplos anteriores, sólo recibió (según Maquiavelo) la ocasión por parte de la fortuna, al ser elegido capitán por un pueblo oprimido (como Moisés y Ciro). Y su acción es resumida en los términos siguientes: eliminó (spense) la milicia antigua y estableció una nueva; abandonó sus amistades y las reemplazó por otras; y, cuando tuvo soldados y amigos plenamente leales, "pudo sobre tales cimientos elevar cualquier edificio" (Maquiavelo, 2011, VI). En algún sentido, este último párrafo ilumina los anteriores, pues el caso de Hierón funciona como formidable guía de acción para el político que aspira a imitar al fundador. Este último no debe corregir edificios antiguos, ni trabajar sobre ellos, sino que debe demoler lo existente, y

5 Podemos agregar a Nabis, mencionado en el capítulo IX del "Príncipe", y cuyos métodos son análogos (comparar con "Discursos", I, 40). Sobre este tema, ver McCormick (2015). En un breve texto dirigido a los Medicis en 1512, poco después de que éstos volvieran al poder, Maquiavelo sugiere -con elegancia- que el nuevo régimen debe apoyarse en el pueblo, liberándose del peso de los notables. Ver: Maquiavelo (1997, Vol. I, pp. 87-89); ver sobre esto: Pancera (2010, IV).

6 Cf. Mansfield (1989, cap. VI).

7 Como dice Cristina Ion, todos los Estados han tenido al menos un momento en el que han dependido de la virtud de un solo hombre. Ver: Ion (2006, pp.93-128). 
emprender luego su aventura desde cero. Dicho de otro modo, el fundador debe tener siempre a su disposición algo así como una página en blanco. Cualquier otra posibilidad lo deja en una situación de fragilidad, pues queda expuesto al orden antiguo. La novedad, para ser tal, ha de ser total. Un poco más tarde (capítulo XIII), Maquiavelo detalla el tipo de métodos utilizados por Hierón: como quería deshacerse de los mercenarios (para tener una milicia propia), los envió a morir a una batalla sin destino ${ }^{8}$. El que quiera ser fundador debe, entonces, instituir un poder que dependa sólo de él, sin fiarse de ninguna lealtad que le preceda. Para lograrlo, debe utilizar todos los medios que sean necesarios. Al fin y al cabo, lo único que tienen en común los cinco casos mencionados por Maquiavelo es una voluntad férrea e inflexible de imponer nuevos órdenes. El fundador es aquel que no retrocede ante nada para cumplir sus propósitos: transformar la materia existente en materia prima, eliminando cualquier principio de distinción en aquella. Si Maquiavelo quiere desacralizar (de allí su tono deliberadamente provocador), es precisamente porque quiere mostrar que ese tipo de acciones aún es posible (y esto conecta desde luego con el enigmático capítulo XXVI, en el que Maquiavelo llama a liberar Italia de los bárbaros ${ }^{9}$ ). Como bien apunta Lefort, la referencia a los fundadores míticos sería de orden simbólico ${ }^{10}$.

Si lo anterior es plausible, entonces debe decirse que la acción política en estado puro -la fundación- se caracteriza por un nivel inaudito de violencia. Convertir al pueblo en materia prima supone indeterminarlo. En los términos de Thomas Berns, la violencia permite la indeterminación del momento originario (Berns, 2001, p. 130). Maquiavelo piensa por primera vez la posibilidad de una fundación químicamente pura, la idea de que la política debe pensarse a partir de un momento cero, y que los políticos realmente dignos de ese nombre logran recrear ese momento. Esa instancia le permite al político moldear un orden en plena libertad, sin determinaciones previas. Se trata de una posibilidad extrema (y excepcional), pero que al mismo tiempo se instituye como regla y criterio, pues todo orden responde a un momento inicial. Más allá de las correcciones que dicho orden pueda recibir con el transcurso del tiempo, el hecho crucial viene dado por ese instante inicial, por ese acontecimiento. Si lo político pende de una indeterminación original, de un acontecimiento puro, entonces no hay estructura teleológica capaz de explicar y sostener el hecho social. Como bien

8 Las fuentes que puede haber utilizado Maquiavelo en lo relativo a Hierón son Justino (XXIII, 4) y Polibio (I, 8-9, 16 y VII, 8).

9 Para Zarka, el capítulo VI y la reflexión sobre la innovación están directamente vinculados con el capítulo XXVI. Ver: Zarka (2001, p. 49).

10 Lefort (1972, p. 363); ver Benner (2013, pp. 85-87). 
lo ha notado Lefort, una de las funciones básicas del capítulo VI es dejar claro que lo político no posee telos fundado en la naturaleza o en la Providencia: no hay un orden político dado ni recibido, sino pura contingencia, y de allí la extrema virtud del fundador ${ }^{11}$. Éste, como observa Höffe, debe adquirir un poder legítimo sin poseer un carácter dinástico ${ }^{12}$. La modernidad política trabaja sobre este preciso punto, que abre un vasto abanico de posibilidades completamente desconocidas para todas las versiones del pensamiento clásico. Lo político es concebido, desde Maquiavelo en adelante, como un artificio superpuesto a una naturaleza que ha perdido toda capacidad de orientación. No hay ninguna naturalidad allí, sino más bien una fuerza externa -la voluntad del fundadorque impone la sociabilidad, bajo el signo del miedo. Esto debe comprenderse en conexión con la teoría maquiaveliana de los humores: toda sociedad, dice, está dividida en dos grupos irreconciliables, aquellos que quieren oprimir y aquellos que no quieren ser oprimidos ${ }^{13}$. De allí que no haya, en Maquiavelo, una visión de la realidad social como algo armónico o natural, sino que está siempre marcada por el signo de la ruptura, del quiebre inicial que siempre puede (y debe) ser reconducido para proveer de unidad al cuerpo social. Lo político se funda en un abismo contingente, y no está enraizado en un supuesto orden natural. En ese sentido, el orden colectivo es más bien una excepción que una regla, y de allí su extrema precariedad. ${ }^{14}$

\section{La figura del príncipe nuevo}

Ahora bien, el texto relativo a los fundadores del capítulo VI tiene un correlato en otros personajes que aparecen en pasajes posteriores del Príncipe. Debemos, eso sí, despejar previamente un equívoco, que guarda relación con los tipos de fundador. Para Pocock, es posible distinguir, al interior del pensamiento maquiaveliano, entre el fundador legislador - que tiene a la vista una comunidad política viable- y el innovador radical -que sólo busca la creación de su propio stato (Pocock, 1975, pp. 156-182; Ion, 2006, p. 107). Naturalmente, esta distinción de Pocock se inscribe en el cuadro de su interpretación de la obra del Florentino, según la cual ésta se encuentra en continuidad con el pensamiento republicano clásico. En ese contexto, no es posible analogar al legislador original, interesado en el bienestar general, con el mero innovador,

11 Lefort (1972, p. 366) e Ion (2006, p. 95).

12 Höffe (2015, pp. 45-60; p. 50).

13 Cf. (2000, IX; 2011, I, 4).

14 Sobre el lugar que ocupa la noción de acontecimiento en la obra de Maquiavelo, ver: Vatter (2014). 
que sólo busca romper. Uno busca crear, mientras que el otro busca su seguridad individual, o la gloria personal. Sin embargo, el capítulo VI no deja espacio para una lectura de ese tipo. Maquiavelo identifica de modo tácito la introducción de nuevos órdenes con la seguridad del fundador. En rigor, Pocock separa los dos tipos de fundadores, porque no ve la ruptura profunda que encarna Maquiavelo (Audier, 2005, pp. 271-273), como si lo político admitiera en él una variante armónica y tradicional, y una segunda rupturista. Pero Maquiavelo no está describiendo el fenómeno específico de la tiranía, como algo cualitativamente distinto de un régimen recto, sino que pretende descubrir un nuevo estatuto de lo político en cuanto tal. La fundación de una comunidad política viable se identifica con la seguridad del fundador porque los nuevos órdenes no pueden instituirse sin esa seguridad, que implica una ruptura total con el pasado y con lo establecido. De hecho, el mismo título del opúsculo alude a esa confusión deliberada que el Florentino busca provocar: el príncipe no es rey ni tirano, sino ambas cosas a la vez. La plasticidad del concepto le permite a Maquiavelo redibujar el problema de los regímenes políticos a la luz de un criterio que no puede comprenderse desde las categorías clásicas (Bénéton, 1996, pp. 27-30).

Un modo de aclarar mejor este punto es detenerse un momento en aquellos personajes que Maquiavelo llama "príncipe nuevo". Se trata de César Borgia, Fernando de Aragón y el emperador romano Séptimo Severo (2000, VII; XIX; XXI). El caso de Borgia es el más llamativo, por varios motivos. Por un lado, la descripción de sus acciones se encuentra en el capítulo VII, esto es inmediatamente después del análisis de la fundación. Un segundo motivo es que Maquiavelo parece considerar a Borgia como un caso especialmente revelador de las posibilidades de la acción política, más allá del fracaso final de su aventura. A sus ojos, Borgia encarna la exploración más acabada de aquello que la situación contemporánea permite, y su derrota final debe ser leída como una invitación a concluir aquella empresa que él no logró llevar a buen puerto.

Ahora bien, el primer problema de Borgia es que, al haber recibido el principado por fortuna y no por virtud, su dominio carece de arraigo. En un principio, Borgia depende de otros y no de sí mismo y, en consecuencia, su posición es extremadamente vulnerable. Pero, y aquí reside su gran virtud, Borgia realiza todos los esfuerzos posibles para girar la situación en su propio favor. El duque trata de modificar las circunstancias para quedar en una situación semejante a la del fundador. Así, reunió (mediante una trampa) a sus enemigos en Sinigaglia, y los asesinó ${ }^{15}$. De este modo, el pueblo al interior del cual diplomáticos entregan muchos más detalles; ver las cartas del 1ํ, 2, 4, 6 y 8 de enero de 1503 (1997, v. II, pp. 778-792). 
había notables y distinguidos (que envidiaban su poder) queda internamente indiferenciado: la materia se vuelve informe. Al mismo tiempo, y al notar el desorden que reinaba en Romaña, Borgia le pide a Ramiro dell'Orco (hombre "cruel y expeditivo") que impusiera disciplina, objetivo imposible de alcanzar sin recurrir a medidas extremadamente violentas. Dell'Orco cumple con lo solicitado, pero se granjea naturalmente el odio del pueblo. Borgia decide entonces juzgarlo, condenarlo a muerte, y exponer luego su cuerpo trozado en Cesena $^{16}$. La ferocidad del espectáculo, concluye Maquiavelo, deja al pueblo "satisfecho y estupefacto" (satisfatti e stupidi) (2000, VII) ${ }^{17}$. De ese modo, Borgia se asegura el respaldo popular, indispensable para el innovador.

Aquí, contrariamente a la sugerencia de Pocock, el innovador radical tiende a identificarse con el fundador, porque la viabilidad política se confunde con la seguridad del príncipe. Si el pueblo ha de quedar satisfecho y estupefacto es porque esa doble disposición permite infundir una forma: la estupefacción satisfecha es una suerte de indeterminación. Por un lado, el estupefacto no tiene reacción, ha sido ganado por la pasividad; y, por otro, el satisfecho ha quedado sin apetito. Esta difícil combinación de disposiciones condensa la difícil proeza a la que está llamado todo político con aspiraciones fundacionales. Más allá del caso particular de Borgia, el objetivo es dejar al pueblo en un estado pasivo y sin apetitos, porque así se le puede infundir libremente una forma. Esto requiere usar la violencia (o, al menos, estar plenamente dispuesto a utilizarla) capaz de generar esas disposiciones. En cualquier caso, al descubrir la extrema violencia que acompaña la fundación política, Maquiavelo también nos obliga a preguntarnos sobre la violencia implícita en las fundaciones a las que se alude en el capítulo VI: los métodos de Ciro, Moisés, Rómulo y Teseo no deben haber sido demasiado distintos de aquellos utilizados por Borgia (Lefort, 1972, p. 372).

Fernando de Aragón, rey de España, es otro de los personajes que recibe el apelativo de príncipe nuevo, y sus acciones son descritas en el capítulo XXI. La apelación es llamativa, pues Fernando es un monarca hereditario, aunque ya conocemos la plasticidad conceptual del Príncipe. En rigor, Maquiavelo está mucho más interesado en las acciones de Fernando que en el origen de su poder; y su acción posee una novedad que lo cautiva. Por de pronto, logra convertirse en monarca poderoso pese a su debilidad inicial; y el principal motivo de este

16 En el capítulo XXI vuelve sobre esto: Che e principi le cose di carico devono fare somministrare ad altri, quelle di grazia loro medesimi.

17 El mismo Maquiavelo dice, en uno de sus informes diplomáticos, haber quedado admirado (en el sentido de paralizado) frente a César Borgia Cf. Maquiavelo (1997, Vol. 2, p. 779). 
éxito es su capacidad de acometer grandes empresas. Esta capacidad no tiene un valor intrínseco, sino que es útil para obtener ciertas disposiciones de parte de los gobernados. Sus acciones son todas muy grandes (grandissime), y algunas extraordinarias (extraordinaria). Maquiavelo explicita su propósito con algunos ejemplos. En primer término, Fernando invadió Granada, y asentó así su Estado, además de mantener ocupadas las mentes de los barones de Castilla. Al pensar en la guerra, dice Maquiavelo, los notables no pensaban en alguna innovación (léase: subversión). La afirmación refuerza la idea de que la fundación debe ser solitaria. Pero Maquiavelo sigue. Mientras los barones estaban concentrados en la guerra, Fernando adquiría reputación e imperio sobre ellos, sin que fueran muy conscientes de aquello. En el fondo, la empresa bélica le permitió a Fernando adquirir dominio sobre los notables sin atacarlos directamente. El rey expulsó también a los marranos, obteniendo así recursos para financiar la guerra, haciendo gala de una "piadosa crueldad". La expresión es digna de ser notada por el contrasentido que sugiere: un príncipe nuevo debe estar dispuesto a utilizar la piedad para lograr sus objetivos, sabiendo que la piedad admite un uso cruel. Esto es buen reflejo de cuán flexible debe ser el príncipe, hasta el punto de encarnar disposiciones aparentemente contradictorias (Maquiavelo, 2000, XV; Manent, 2007, pp. 21-22). Las acciones extraordinarias de Fernando, continúa el Florentino, mantienen en suspenso y admiración a sus súbditos (o sea: sin reacción). Vemos aquí, en una exposición muy condensada (son unas pocas líneas), muchos de los elementos que habían aparecido en el tratamiento de Borgia: uso inteligente de la violencia (que busca producir determinados resultados), y obtención de una disposición pasiva de los gobernados ${ }^{18}$. Es relevante notar que las grandes acciones son un distractivo tanto para los grandes como para el pueblo, pues ambos grupos aceptan finalmente la innovación (aunque por motivos diferentes). Y es precisamente a partir de ese logro que puede decirse que Fernando es algo así como un príncipe nuevo: pese a ser hereditario, logra generar las condiciones propias de la fundación. Naturalmente, y tal como ocurría con Borgia, esto conecta directamente con el último capítulo del Príncipe: las grandes acciones todavía son posibles, y lo son desde múltiples lugares y posibilidades. Por lo mismo, la otra lección implícita en el tratamiento de Fernando es que la novedad puede adquirir manifestaciones muy variadas: Fernando no elimina a los notables ni expone el cuerpo trozado de uno de sus cómplices en la plaza. No hay, en Maquiavelo, un recetario práctico ni una casuística estricta que indique cómo acercarse a la posición 
del fundador (Bénéton, 2012), pero sí elementos comunes: hay que ejercer violencia de algún tipo para generar disposiciones pasivas en la población, pero hay muchos modos de hacerlo. Dado que la voluntad del fundador juega un papel fundamental, la política tiene una dimensión creativa muy relevante: cada innovador debe inventar su propio modelo.

Severo es el otro personaje que, en el capítulo XIX del opúsculo, recibe el apelativo de príncipe nuevo. Recordemos que, según Leo Strauss, este capítulo constituye la cima del tratado (Strauss, 1978, p. 60). Entre otras cosas, Maquiavelo detalla allí las acciones de una serie de emperadores romanos. Estos gobernantes merecen atención porque debieron enfrentar una dificultad singular, que no todos los príncipes conocen. En efecto, ellos no sólo deben manejar los dos apetitos sociales más comunes (ricos y pobres), sino que también han de considerar un tercer apetito particularmente voraz, el de los militares. El humor militar es cruel y avaro, y además posee la fuerza. Sabemos que el consejo de Maquiavelo, respecto de los dos primeros humores, es que el príncipe debe privilegiar al pueblo, pues así consolida mejor su poder interno. Ahora bien, las condiciones cambian si la sociedad contiene además un humor militar poderoso. Dado que es imposible satisfacer al mismo tiempo las tendencias popular y militar (que apetecen cosas distintas), se hace necesario privilegiar a aquellos que tienen mayor fuerza. Sin embargo, tal medida está lejos de ser suficiente: la utilidad de la alianza con los militares depende de la capacidad del príncipe para conservar su reputación entre los soldados. Nótese bien la dificultad: no basta con dar rienda suelta a la avaricia y la crueldad de los soldados para conservar la reputación debida. Ésta es solamente la condición de posibilidad de ejercicio del poder porque, sin ella, los militares no respetarían al príncipe.

El emperador que más llama la atención de Maquiavelo es Severo, pues logra una extraña combinación. Su gran virtud es haber logrado satisfacer tanto el apetito militar como el popular. Esto es difícil, pues -como vimosambas tendencias son difícilmente compatibles. Con todo, Severo logra ser respetado tanto por los soldados como por el pueblo (a pesar de que éste fue oprimido). Su virtud, dice Maquiavelo, lo hacía admirable a los ojos del pueblo y de los militares: los primeros quedaban "estupefactos y atónitos" (stupidi e attoniti), y los segundos "reverentes y satisfechos" (reverenti e satisfatti) ${ }^{19}$. Estos adjetivos recuerdan, desde luego, los utilizados al hablar de Borgia. Hay aquí un triángulo, constituido por el príncipe y los dos humores que deben 
ser manejados. Los humores sociales son tumultuosos, y están naturalmente inclinados a provocar desorden dada la condición humana. Allí donde hay también un humor militar, la ecuación se complica: la prioridad es satisfacer a los soldados, que suelen ser licenciosos y crueles. Sin embargo, el exceso de crueldad cosecha un odio peligroso. El objetivo es entonces satisfacer a unos sin ganarse el odio de otros. En otras palabras, dejar a dos humores contrarios en un estado de pasividad: unos atónitos, y los otros satisfechos; unos estupefactos, y los otros reverentes. Severo logra neutralizar el tumulto y el desorden, pues deja a todos los sectores relevantes de la sociedad en admiración (pasiva) respecto de su persona.

En virtud de lo anterior, se gana el calificativo de príncipe nuevo, que el opúsculo reserva a tan pocas figuras. Severo supo ser león y zorro, que es la condición de éxito que había sido enunciada en el capítulo inmediatamente anterior (XVIII). Mediante un uso ejemplar de violencia y disimulación, fue eliminando los múltiples obstáculos que encontró su camino. En palabras de Lefort, supo darle a la violencia ejercida una apariencia de legitimidad (Lefort, 1972, p. 421). El factor decisivo de la acción de Severo reside en la extrema plasticidad de su carácter, que le permite satisfacer a humores diversos ${ }^{20}$. Severo debe poner a una sociedad llena de complejidades internas en estado de fundación, lo que implica un grado importante de pasividad, y allí está su proeza (que parece ser más admirable que las fundaciones del capítulo VI) ${ }^{21}$. Y esto nos conduce nuevamente al quiebre con Aristóteles. Si éste valora ante todo la estabilidad del carácter, para Maquiavelo las cosas son distintas: la naturaleza del poder político obliga a tener varias máscaras, a tener varias naturalezas. En ese contexto, los hábitos arraigados son un obstáculo más que una ayuda. De aquí el consejo que el Florentino repite acerca de la Fortuna: hay que saber cambiar con ella, pues las disposiciones deben adaptarse a los contextos cambiantes (Maquiavelo, 2011, p. 25). Severo era "un león muy feroz y un zorro muy astuto” y, para obtener el poder, manipuló, mintió y engañó; $y$, sin embargo, conservó siempre una gran reputación.

20 Herodiano insiste en la capacidad de simulación de Severo. Ver (2011, II, 9, 10-39) (“Era un extraordinario maestro en el arte de simular, y no ahorraba ningún juramento, aunque fuera preciso violarlo con vistas a obtener alguna ventaja; su boca pronunciaba lo que no sentía su corazón").

21 De más está decir que Maquiavelo no alude a ninguna de las críticas que Herodiano formula a propósito de Severo. Por un lado, al permitir a los militares habitar con sus mujeres, Severo "fue sin duda el primero en trastornar la gran fortaleza y autoridad de su forma de vida y su obediencia antes las penalidades y el disciplinado respeto por sus jefes, enseñándoles a desear las riquezas y conduciéndolos hacia una vida de molicie" (2011, III, 8, 5). Y, por otro lado, desarrolló una codicia excesiva: "La severidad con sus enemigos no era más que un pretexto; en realidad, su codicia se había desbordado. Jamás un emperador fue tan esclavo del dinero" (2011, II, 8, 7). 


\section{La fundación y la cuestión de los humores}

La figura del príncipe nuevo, encarnada por esos tres ejemplos, permite comprender mejor la dificultad a la que alude Maquiavelo en el capítulo VI, sobre la dificultad de introducir nuevos órdenes. El primer problema guarda relación con el carácter contingente del orden político. Dado que no hay un orden natural, esto es, una naturaleza que oriente teleológicamente hacia la polis o hacia algún orden, el fundador es de algún modo el creador de algo absolutamente nuevo, pues su innovación rompe con la insociabilidad espontánea del hombre. Recordemos que, para el Florentino, el deseo de adquirir es natural y que, además, los hombres viven en un constante estado de frustración pues sus deseos son infinitos e imposibles de satisfacer ${ }^{22}$. Los hombres no están en ningún caso predispuestos a cooperar o ponerse de acuerdo, sino que resisten el "advenimiento de la comunidad", según la expresión de Lefort (1972, p. 366). El político auténtico es entonces aquel que contraría el desorden producido por los apetitos humanos, aquel que nos fuerza a unirnos a pesar de nuestras inclinaciones. Esto deja, desde luego, a Maquiavelo cerca de Hobbes, quien elabora la teoría del Estado moderno precisamente a partir de estas premisas: el Leviatán es el gran instrumento que permite pacificar a una humanidad que, de lo contrario, viviría en perpetuo estado de guerra. Sin embargo, subsiste entre ellos una diferencia fundamental y difícil de soslayar. En efecto, el secretario florentino no cree que sea posible concebir una solución definitiva al problema político: la contingencia y la precariedad de lo político son siempre más fuertes que nuestro ingenio ( $C f$. Ménissier, 2010, p. 141). ${ }^{23}$ Esta fragilidad implica que la tarea de fundador es titánica, pues debe poner orden allí donde, en un principio, no hay sino conflicto, caos y desorden. La fundación trasciende la naturaleza y la tradición, y no hay institución capaz de domesticar la humanidad (Ménissier, 2010, p. 291).

El conflicto tiene, en cualquier caso, su propia lógica. No es completamente indeterminado, pues se organiza en función de algunos criterios estables. Como hemos visto, estos criterios tienen que ver con los humores sociales y con la

22 "El deseo de adquirir es, verdaderamente, algo muy natural y ordinario" (2000, III); "La naturaleza creó a los hombres de modo tal que pueden desear todo y no pueden obtenerlo todo; así que, el deseo siendo siempre superior al poder de adquirir, el resultado es frustración de lo que se posee, y la poca satisfacción de lo que se tiene" (2011, I, 37).

23 Hobbes llega a decir lo siguiente: "And as the art of well building is derived from principles of reason, observed by industrious men that had long studied the nature of materials, and the diverse effects of figure and proportion, long after mankind began, though poorly, to build: so, long time after men have begun to constitute Commonwealths, imperfect and apt to relapse into disorder, there may principles of reason be found out, by industrious meditation, to make their constitution, excepting by external violence, everlasting" (Leviatán, XXX). 
división, propia de todo grupo humano, entre aquellos que oprimen y aquellos que desean no ser oprimidos (sabemos que, a veces, se suma el humor militar). Como ha señalado Lefort, "la interrogación sobre el principio es indisociable del descubrimiento de una división originaria del cuerpo social”, pues los apetitos humanos se materializan en esa división (Lefort, 1972, pp. 721-722). Desde luego, en el caso del fundador primigenio esta división social no se encuentra consolidada, y sólo está en potencia, si se permite la expresión. En ese sentido, la tarea del innovador tiene una dificultad añadida: trabaja sobre una sociedad cuyos humores ya están consolidados, y tienen su propia inercia. Como fuere, los apetitos humanos no existen fuera de ese binomio. El hecho es que todo príncipe debe lidiar con esta división; más aún, debe tomar posición frente a ella, porque resulta imposible satisfacer simultáneamente a todos los humores. La sociedad está dividida estructuralmente en dos disposiciones humanas antinómicas e irreconciliables, y que incluso pueden llegar a ser tres. El fundador se ubica a distancia de esos humores, sin participar directamente de ninguno de ellos. Desde su posición externa, debe intentar encontrar una situación que le permita asegurar su poder, sabiendo que éste no está nunca garantizado de modo definitivo: los apetitos están en perpetuo movimiento y, por tanto, es necesario estar siempre abiertos a esa dinámica. En ese sentido, el orden es la excepción, y no está inscrito en la configuración de la naturaleza. La fundación política es, ante todo, un intento siempre contingente por manejar ese abismo que separa y vuelve adversarios a los hombres (Cf. Vatter, 2013, pp. 63-64).

Tampoco hay una justicia implícita que descubrir en la situación, como si esa escisión social ocultara una moralidad que la autoridad estuviera en condiciones de discernir. Recordemos que Aristóteles es perfectamente consciente de la división, pero cree que lo propio de la autoridad política es tomar decisiones que propicien -aunque fuera imperfectamente- el interés común. La respuesta política es, para Aristóteles, un esfuerzo por encontrar el camino justo en medio de la contingencia y de la división ( $C f$. Terrel, 2015). Para Maquiavelo, eso simplemente no es posible, porque la división es de tal radicalidad que, propiamente hablando, no hay justicia posible. Por lo mismo, la tarea del fundador no consiste en encontrar una salida que estuviera de algún modo implícita en la realidad misma, sino plasmar su propia voluntad. En rigor, la realidad no tiene en sí misma un equilibrio propio por descubrir, sino que el orden le debe ser impuesto externamente, por la voluntad de alguien que ha tomado distancia respecto de la sociedad. ¿Qué tipo de configuración de los humores permite seguir el ejemplo de Hierón, esto es, poner los primeros fundamentos de un edificio? Ésa es, en el fondo, la única pregunta que merece 
ser formulada, y su respuesta no reside en la naturaleza. En este sentido, es correcto decir que el fundador no debe poseer virtudes ni hábitos. Los hábitos conforman una segunda naturaleza, e impiden tener la plasticidad necesaria para adaptarse a las exigencias de un entorno imprevisible (como muestra el ejemplo de Severo). La acción política pasa a ser una actividad transitiva y técnica, donde lo importante es el resultado que se logra más que la perfección de los gobernantes y ciudadanos ( $C f$. Manent, 2007, pp. 303-316). O, dicho de otro modo, la perfección sólo es pensable en función de la gloria. La política deja así de ser, propiamente hablando, acción, y se convierte en producción: ya no es una operación que, para emplear los términos de Tomás de Aquino, "permanece en el que obra" (Aquino, 2001, pp. 34-35). Esta subversión de la praxis tiene otra dimensión, que ha sido bien notada por Thierry Ménissier, $\mathrm{y}$ que está contenida en la apología maquiaveliana de la acción y de la libertad creadora del político. Hay allí una ruptura con la prudencia tradicional, pues la acción misma se vuelve prioritaria respecto del cálculo o la deliberación. Para dominar la Fortuna, resulta imprescindible anticiparse a ella, y abrirse a la novedad radical del acontecimiento. Hay, en Maquiavelo, una considerable sobrevalorización de la praxis y de sus posibilidades: el gesto instruye la decisión, y no a la inversa, porque la realidad no ha de ser comprendida antes de la acción, sino que sólo la acción puede intentar ordenar el caos inicial. Si no hay orden natural, sólo la acción del fundador puede introducir normatividad en el mundo, ciertamente desde la comprensión del conflicto humano original. Sin embargo, para lograrlo, la noción clásica de prudencia no le sirve de mucho, pues ésta supone que la realidad puede ser de algún modo comprendida ( $C f$. Menissier, 2010, pp. 292-295) ${ }^{24}$. En otras palabras: la voluntad del fundador precede y gobierna a la prudencia.

Ahora bien, y como vimos, el desafío es especialmente difícil para aquel que no encuentra la misma ocasión que los primeros fundadores. La dificultad reside en que los apetitos están ya consolidados, y tienen una inercia difícil de modificar. Intervenir esa rutina es una tarea arriesgada, y establecer nuevos órdenes lo es en grado sumo. En términos simples, la pregunta puede plantearse del modo siguiente: ¿cómo puede un político sin ocasión perfecta encontrar la misma libertad de acción que el fundador primigenio, cómo puede intervenir el equilibrio siempre precario de los humores en su provecho? Maquiavelo

24 Por lo mismo Ménissier habla de una teología política Maquiaveliana. Por su parte, Miguel Vatter señala que Maquiavelo descubrió la libertad de la praxis humana, y que le dió autonomía a la acción al liberarla de la noción de prudencia (2014, pp. 1 y 140). En este sentido, Carl Schmitt es un discípulo aventajado de Maquiavelo, Cf. Schmitt (2009). 
responde esta pregunta en términos que no deberían minimizarse: la primera tarea del político que aspira a fundar es librarse de todos quienes envidian su poder. Hierón, Borgia, Nabis, Cleómenes; todos ellos ilustran que no debe haber escrúpulos a la hora de asesinar a los eventuales competidores, provocando de paso miedo en el resto de la población.

Recordemos también que varios de los ejemplos propuestos por Maquiavelo parecen hacernos sentir que la fundación no es algo que esté tan fuera de nuestro alcance; o que, al menos, la fundación admite diversas posibilidades. Esto no debe extrañar: si la condición más propia de la política es la contingencia y la precariedad, entonces el orden colectivo exige constantemente ser refundado. De algún modo, la política misma contraría constantemente nuestros impulsos naturales. En consecuencia, la tarea fundacional es propia de un Sísifo, y siempre debe ser actualizada porque no hay orden que perdure: la política contradice nuestras inclinaciones. Esto tampoco guarda relación con el régimen, pues tanto la república como el principado exigen esa actualización (aunque puede admitir manifestaciones diversas). Esto queda claro si recordamos la enseñanza de Maquiavelo en Discursos III, 1. Allí, el secretario florentino afirma que las repúblicas deben volver sistemáticamente a sus inicios para librarse de la corrupción. Volver a los inicios significa recrear de algún modo el momento fundacional, para poder recrear también sus efectos. Las personas son naturalmente codiciosas y conflictivas, y sólo el recuerdo del miedo original permite la obediencia: el volver a los inicios implica infundir temor en la población. Maquiavelo incluso se da el lujo de prescribir un plazo de tiempo; al menos cada diez años, los hombres deben ser devueltos a esa situación. De lo contrario, se acomodan, se olvidan y se vuelven ambiciosos; esto es, dejan de ser materia dispuesta a recibir una forma ${ }^{25}$. Por supuesto, como bien apunta Lefort, el regreso a los orígenes no es una pura y simple imitación, sino una actualización del principio, pues el orden debe ser refundado constantemente $(1972, \text { p. } 658)^{26}$. Por eso no hay reposo posible, no hay armonía que dure sin el esfuerzo sistemático de una voluntad por actualizarlo. Debe haber, más bien, repetición constante de ejecuciones que permitan una recreación constante del momento fundacional. Si se confía en la bondad de los hombres, se termina como Piero Soderini, quien perdió a la vez su patria, su poder y su reputación cuando volvieron los Medicis ${ }^{27}$.

25 En Discursos, I, 29, Maquiavelo dice lo siguiente: "los hombres, por miedo al castigo, se mantienen más tiempo libres y menos ambiciosos".

26 Ver también (Ion, 2006, p. 103).

27 Según Maquiavelo, Soderini creía que su paciencia y bondad podían terminar con las malas intenciones de sus enemigos (2011, III, 3). 
Estas consideraciones pueden contribuir a iluminar el enigmático capítulo XXVI del Príncipe, en el que Maquiavelo llama a los Medicis a imitar a los fundadores mencionados en el capítulo VI y a liberar Italia. Es evidente que dicho texto contiene una buena dosis de retórica, y aquello se hace evidente -por ejemplo- en el modo en que Maquiavelo minimiza las dificultades de la empresa (después de haber dicho que no hay nada más peligroso que la introducción de nuevos órdenes). La ocasión, dice el Florentino, es aún más favorable que la que tuvieron Moisés, Rómulo, Ciro y Teseo ${ }^{28}$. Maquiavelo vuelve a insistir además en la fórmula del capítulo VI: habla de la inédita posibilidad de introducir una forma en la materia; y dice luego que en Italia "no falta materia a la que dar forma". La alusión es explícita: existe la ocasión para recrear una fundación, en todo caso, es posible al menos intentarla. Maquiavelo también rebaja nuevamente a los fundadores primigenios: aunque es cierto que fueron extraordinarios, "al fin y al cabo fueron hombres". La posibilidad fundacional no está tan lejos, sólo requiere una voluntad férrea, capaz de sobreponerse a los obstáculos e infundir la esperada forma. El gran obstáculo es, desde luego, la moral y tradición cristiana que obstaculizan una acción de esa naturaleza, y que ha vuelto imposible la imitación del gesto romano: Maquiavelo sugiere que una nueva fundación merece ser intentada, y que ella tiene que superar los límites impuestos por el cristianismo ( $C f$. Ion, 2006, p. 114). Si se quiere, y más allá de los Medicis, el último capítulo del Príncipe intenta rehabilitar la posibilidad de una acción política digna de ese nombre: fundar siempre es posible. La única condición es poseer la voluntad necesaria, y el caso de Fernando demuestra que la innovación admite múltiples caminos. La política moderna se abre así con un llamado a recuperar la capacidad política, que la larga Edad Media había ocultado a través de una infinita dispersión del poder $^{29}$. La dificultad estriba, como lo ha notado finamente Cristina Ion, en la tensión siguiente: el puro y simple retorno a la virtud antigua es imposible dada la introducción del cristianismo ${ }^{30}$. El proyecto de Maquiavelo, en ese contexto,

28 "Habiendo considerado, pues, todas las cosas que hasta ahora se han dicho, y pensando para mí si en Italia, actualmente, corrían tiempos que permitieran a un nuevo príncipe adquirir honor, y si había aquí materia que diera a un hombre prudente y virtuoso la oportunidad de introducir en ella una forma que le honrara a él y proporcionara bienestar a todos los hombres que en ella viven, me parece que concurren tantas cosas en favor de un príncipe nuevo, que no creo que haya habido nunca un momento más apto que este (che io non so qual mai tempo fussi più atto a questo) [...] Y hay ahora una gran disposición; y donde hay tan gran disposición no pueden existir demasiadas dificultades" (XXVI, el destacado es nuestro). Para Strauss, todo esto es irónico, pues Maquiavelo sería demasiado consciente de las múltiples dificultades que enfrentaría una empresa de esa naturaleza. Ver: Strauss (1978, p. 72).

29 Cristina lon ha notado, con pertinencia, que la fundación a la que llama Maquiavelo pasa por la liquidación de los restos anárquicos del mundo medieval. Ver: Ion (2006, p. 90).

30 Ibid., p. 114. 
no puede ser leído, como un simple intento por recuperar la virtud pagana, sino más bien por elaborar una virtud post-cristiana. De allí la radicalidad implícita en su filosofía, que tantas perspectivas abre al pensamiento moderno y contemporáneo. De algún modo, Maquiavelo no hace más que vislumbrar la profundidad del conflicto teológico político latente a fines de la Edad Media, abriendo así la modernidad política.

\section{Bibliografía}

AQUINO, T. "Suma de Teología”. Ed. F. Barbado, 16 Vols. Madrid: BAC, 1964.

. "Comentario a la Política de Aristóteles". Ed. A. Mallea. Pamplona: Eunsa, 2001. ARISTÓTELES. "Política". Edición de Manuela García Valdés. Madrid: Gredos, 2007. . "Ética a Nicómaco/Ética Eudemia". Edición de Julio Pallí Bonet. Madrid :

Gredos, 1993.

AUDIER, S. "Machiavel, conflit et liberté". París: VRIN-EHESS, 2005.

BÉNÉTON, Ph. "Les régimes politiques". Paris: Puf, 1996.

"The Kingdom Suffereth Violence: The Machiavelli/Erasmus/More

Correspondence and Other Unpublished Documents". South Bend, IN: St. Augustine's

Press, 2012.

BENNER, E. "Machiavelli's Prince. A New Reading”. Oxford: Oxford University Press, 2013.

BERNS, T. "L'originaire de la loi chez Machiavel”. En: G. Sfez, M. Senellart (eds.), "L'enjeu Machiavel". París: Puf, pp. 123-140, 2001.

CRUZ-PRADOS, Alfredo. "La sociedad como artificio. El pensamiento político de Hobbes". Pamplona : Eunsa, 1986.

HÖFFE, O. "L'amoralité par provision dans Le Prince de Machiavel". En: Y-Ch. Zarka, C. Ion (eds.), "Machiavel: le pouvoir et le peuple”. Milán: Mimésis, 2015, pp. 49-60. ION, C. "Conquérir, se fonder, maintenir".En M. Gaille-Nikodimov, T. Ménissier (eds.), "Lectures de Machiavel". París: Ellipses, 2006, pp. 93-128.

LEFORT, C. "Le travail de'lœuvre Machiavel”. París. Gallimard, 1972. pp. 425 y passim. MANENT, P. "Naissances de la politique moderne. Machiavel, Hobbes, Rousseau". París: Gallimard, 2007. . "Enquête sur la démocratie". París: Gallimard, 2007.

MANSFIELD, H. "Taming the Prince. The Ambivalence of Modern Executive Power". Nueva York: Free Press, 1989.

MAQUIAVELO. "Le prince", edición de J-L Fournel y C. Zancarini. París : Puf, 2000. . "Opere". Ed. C. Vivanti, 3 vols. París: Einaudi-Gallimard, 1997.

. "Obras". Ed. J. M. Forte. Madrid : Gredos, 2011.

MCCORMICK, J. "Le tyran grec en réformateur de la république chez Machiavel". En Y-Ch. Zarka, C. Ion (eds.)."Machiavel: le pouvoir et le peuple”. Milán: Mimésis, 2015, pp. 61-74.

MÉNISSIER, T."Machiavel ou la politique du centaure". París : Hermann, 2010. 
PANCERA, G., "Maquiavel entre Repúblicas". Belo Horizonte: UFMG, 2010.

POCOCK, J. "The Machiavellian Moment. Florentine Political Thought and the Atlantic Republican Tradition". Princeton : Princeton University Press, 1975.

ROECKELIN, R. "Machiavelli and Epicureanism. An Investigation into the Origins of Early Modern Political Thought". Landham, MD: Lexington Books, 2014.

SCHMITT, C., "Teología política". Madrid: Trotta, 2009.

SIMPSON, P. "A Philosophical Commentary on the Politics of Aristotle”. Chapel Hill, NC: The University of North Carolina Press, 1998.

STRAUSS, L. "Thoughts on Machiavelli". Chicago: The University of Chicago Press, 1978.

TERREL, J. "La Politique d'Aristote. La démocratie à l'épreuve de la division sociale". Vrin, 2015.

VATTER, M. Machiavelli's The Prince. Bloomsbury, 2013.

VATTER, M. "Between Form and Event. Machiavelli's Theory of Political Freedom". Nueva York: Fordham University Press, 2014.

ZARKA, Ch.-Y. "Chapitre VI du Prince. L'innovation en politique", en T. Ménissier, Ch-Y. Zarka (eds.), "Machiavel. Le Prince ou le nouvel art politique". París : Puf, 2001, pp.47-58. 